\title{
Microalbuminuria in Saudi Adults with Type 1 Diabetes Mellitus
}

\author{
Khalid S Aljabri ${ }^{1}$, Samia A Bokhari ${ }^{1}$, Muneera A Alshareef ${ }^{1}$, Patan M Khan ${ }^{1}$ and Bandari K Aljabri ${ }^{2}$ \\ ${ }^{1}$ Department of Endocrinology, King Fahad Armed Forces Hospital, Saudi Arabia \\ ${ }^{2}$ Um Al Qura University, College of medicine, Saudi Arabia \\ *Corresponding author: Khalid SJ Aljabri, Department of Endocrinology, King Fahad Armed Forces Hospital, Jeddah-21159, Saudi Arabia
}

Submission: 些 May 14, 2018; Published: 觜 June 15, 2018

\begin{abstract}
Background: Diabetes mellitus is among the most common chronic non-communicable diseases. The development of microalbuminuria in type 1 diabetes increases the risk for renal and cardiovascular disease.

Methods: A cross sectional study was conducted at the Primary Health Care Clinics at King Fahad Armed Forces Hospital, Jeddah, Saudi Arabia. A total of 334 Saudi with type 1 diabetes were randomly selected.

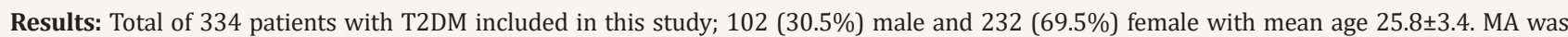
present in 99 (29.6\%). MA was not significantly more prevalent in female (69.4\%) with female predominance (sex ratio male: female) 1:2.3. HTN with MA was significantly more prevalent in 51(51.5\%) of MA group with odd ratio 1.7 (1.2-2.4), p=0.001 with no siginificant difference between both gender. Patients with MA have significant higher HbA1c than patients with normal buminuria and there was a significant difference between gender $(\mathrm{p}<0.0001)$ and when compared to HbA1c groups $(\mathrm{p}=0.002)$.
\end{abstract}

Conclusion: The frequency of microalbuminuria in patients with type 1 diabetes in this study is high. It is mandatory to have adequate diagnostic, therapeutic and educational resources in addition to competent physicians who can manage microalbuminuria in diabetic patients by using a continuing, comprehensive and coordinated approach.

Keywords : Type 1 diabetes; Microalbuminuria

\section{Introduction}

Diabetes is one of the largest health emergencies of the 21st century. The International Diabetes Federation Diabetes Atlas estimated that in 2015, there were 415 million patients with diabetes worldwide and by 2040 this figure will rise to 642 million people. Type1 diabetes (T1DM) is less common, accounting for $7-12 \%$ of the total cases and it is still increasing by approximately $3 \%$ each year globally, particularly among children [1]. T1DM leads to an increased risk of morbidity and early mortality due to chronic complications affecting both the micro-and microvasculature [2]. Diabetic nephropathy (DN) is one of the most serious chronic complications of T1DM, affecting approximately $20-30 \%$ of patients and increasing the risk of cardiovascular disease and endstage renal disease $[3,4]$. The incidence of microalbuminuria (MA) in T1DM individuals varies greatly among different populations. There is a racial difference in prevalence of DN and end stage renal failure. MA is a common finding in T1DM and is found in $30-60 \%$ of patients with a diabetes duration of 10-20 years [5-8]. MA is defined as an albumin excretion rate of $20-199 \mathrm{~g} / \mathrm{min}$ in a timed or a 24 -h urine collection (equivalent to $30-299 \mathrm{mg} / \mathrm{g}$ creatinine in a random spot sample) [4].

In adults with T1DM MA is an early marker of structural renal disease and a risk factor for the development of macroalbuminuria $[9,10]$. The presence of macroalbuminuria is associated with subsequent development of end stage renal disease and increased coronary mortality [11-13]. After about 18 years of diabetes the cumulative prevalence of MA is 34\%5. 6,13MA occurs in association with poor glycaemic control, elevated blood pressure and longer diabetes duration. It is important to assess factors related to the development of MA in young people with T1DM in order to identify whether such changes are due to underlying renal pathology or may be related to functional changes. Renal haemodynamic changes may occur during pubertal growth and development or may reflect uncontrolled diabetes and glycaemic variability, both of which are common during puberty [14-16].

In consistence with the global significant increase in incidence of T1DM of almost 3\% per year Therefore we anticipate a parallel 
increase in the rate of complications, including DN. DN is more prevalent among African Americans, Asians, and Native Americans than in Caucasians [17-21]. The frequency and risk factors of MA are not fully described among adults with T1DM in our region. The identification of such individuals is an important challenge to care providers. This single center study reports the prevalence of DN in adults with T1DM in Saudi Arabia and explore the risk factors associated with it. In this study, we report on the frequency of MA in T1DM patients attending a diabetes centre in Saudi Arabia.

\section{Methods}

A cross sectional study was conducted at the Primary Health Care Clinics at King Fahad Armed Forces Hospital. A total of 334 Saudi with T2DM were randomly selected. The demographic data and medical history were documented. Blood pressure readings were performed within a gap of 15 minutes using a mercury sphygmomanometer by palpation and auscultation method in right arm in sitting position. Two readings were taken 15 minutes apart and the average of both the readings was taken for analysis. Hypertension (HTN) was also diagnosed based on antihypertensive medications or having a prescription of antihypertensive drugs and were classified as Hypertensive irrespective of their current blood pressure reading or if the blood pressure was greater than 140/90mmHg based on American College of Cardiology/American Heart Association Task Force on Clinical Practice Guidelines [22]. The HbA1c was divided into three groups; $<7.0,7.0-8.9$ and $\geq 9.0$. MA was assessed by measurement of mean albumin excretion rate (AER) on timed, overnight urine collections. Fasting serum lipids were done on a sample of blood after fasting for 14 hours. The method used for determining the cholesterol and triglyceride levels in the laboratory was the Enzmatic method. Albumin was measured using a polyclonal radioimmunoassay. MA was defined as AER 30g/ min in overnight urine collections (equivalent to $30-299 \mathrm{mg} / \mathrm{g}$ creatinine in a random spot sample).

\section{Statistical analysis}

Univariate analysis of baseline and follow up demography and clinical laboratory endpoints were accomplished using unpaired t-test. Chi square $\left(\mathrm{X}^{2}\right)$ test were used for categorical data comparison. Pearson's correlations between continuous variables were used as a measure of association. All statistical analyses. Were performed using SPSS Version 22.0. All P values were based on twosided tests where $\mathrm{P}<0.05$ was considered statistically significant.

\section{Results}

A total of 334 patients with T2DM included in this study; 102 (30.5\%) males and 232 (69.5\%) females with mean age 25.8 \pm 3.4 , (Table 1). MA was present in 99 (29.6\%). MA was not significantly more prevalent in female $(69.4 \%)$ with female predominance (sex ratio male: female) 1:2:3. HTN with MA was significantly more prevalent in 51(51.5\%) of MA group with odd ratio 1.7(1.2-2.4), $\mathrm{p}=0.001$ with no siginificant difference between both gender, (Figure 1). Patients with MA have significant higher HbA1c than patients with normoalbuminuria and there was a significant difference between gender $(\mathrm{p}<0.0001)$ and when compared to HbA1c groups ( $\mathrm{p}=0.002)$-see (Figure $2 \& 3$ ).

Table 1: Demographic patients parameters and Comparison of features between microalbumin groups.

\begin{tabular}{|c|c|c|c|c|}
\hline \multicolumn{2}{|c|}{ Parameters } & $\begin{array}{l}\text { Normoalbuminuria } \\
\qquad 235(70.4)\end{array}$ & $\begin{array}{c}\text { Microalbuminuria } \\
99(29.6)\end{array}$ & $P$ value \\
\hline \multirow[t]{2}{*}{ Gender } & Male & $71(30.3)$ & $30(30.6)$ & \multirow[t]{2}{*}{0.9} \\
\hline & Female & $163(69.7)$ & $69(69.4)$ & \\
\hline \multicolumn{2}{|c|}{ Age(years) } & $32.3 \pm 6.6$ & $26.3 \pm 3.0$ & 0.09 \\
\hline \multicolumn{2}{|c|}{ Body mass index $\left(\mathrm{kg} / \mathrm{m}^{2}\right)$} & $75(59.5)$ & $31.2 \pm 6.0$ & 0.2 \\
\hline \multicolumn{2}{|c|}{ Hypertension } & $7.5 \pm 2.2$ & $51(40.5)$ & 0.001 \\
\hline \multicolumn{2}{|c|}{ HbA1c } & $63.6 \pm 14.9$ & $8.6 \pm 2.5$ & $<0.0001$ \\
\hline \multicolumn{2}{|c|}{ Serum creatinine (umol/l) } & $10.1 \pm 7.0$ & $64.1 \pm 16.3$ & 0.8 \\
\hline \multicolumn{2}{|c|}{ Urine microalbumin $(\mathrm{g} / \mathrm{min})$} & $5.0 \pm 1.0$ & $185.1 \pm 385.0$ & $<0.0001$ \\
\hline \multicolumn{2}{|c|}{ Total cholesterol (mmol/l) } & $2.9 \pm 0.9$ & $4.9 \pm 1.1$ & 0.9 \\
\hline \multicolumn{2}{|c|}{ Low density lipoprotein (mmol/l) } & $1.9 \pm 1.9$ & $2.9 \pm 0.9$ & 0.9 \\
\hline \multicolumn{2}{|c|}{ Triglyceride (mmol/l) } & $1.2 \pm 0.3$ & $2.0 \pm 1.3$ & 0.6 \\
\hline & & $1.2 \pm 0.3$ & $1.2 \pm 0.3$ & 0.9 \\
\hline
\end{tabular}

Data are number (\%) and mean standard \pm deviation 


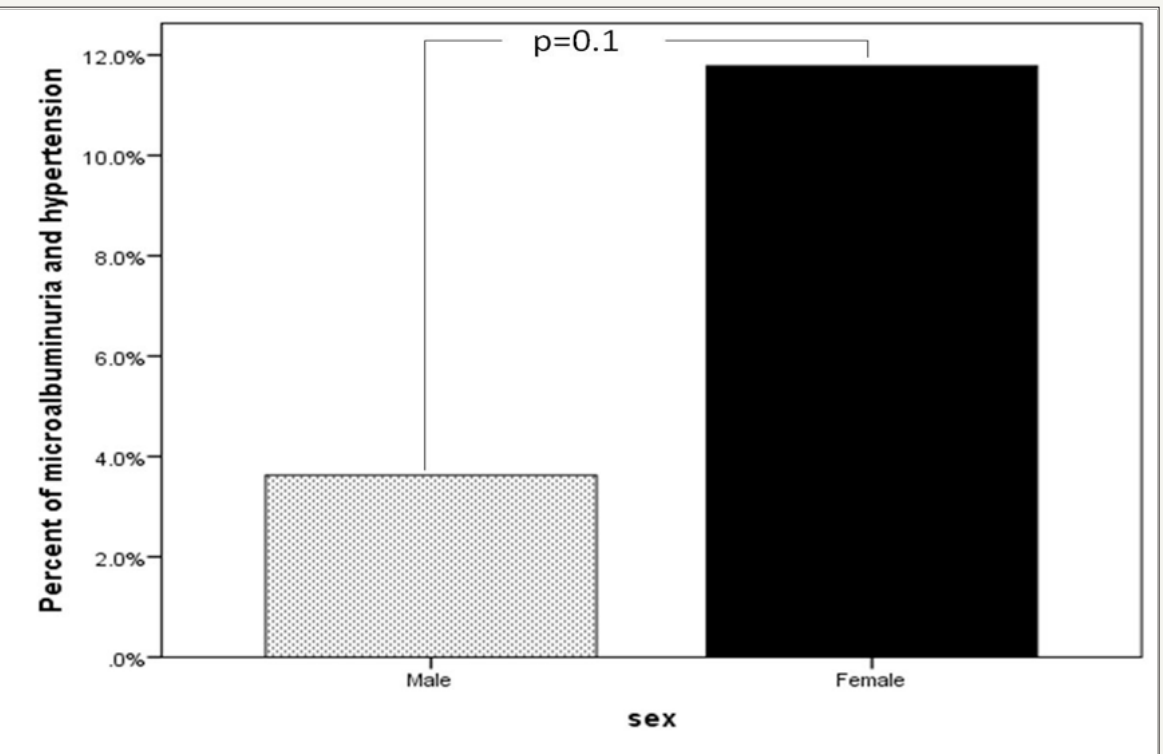

Figures 1: Frequency of microalbuminuria and hypertension according to gender.

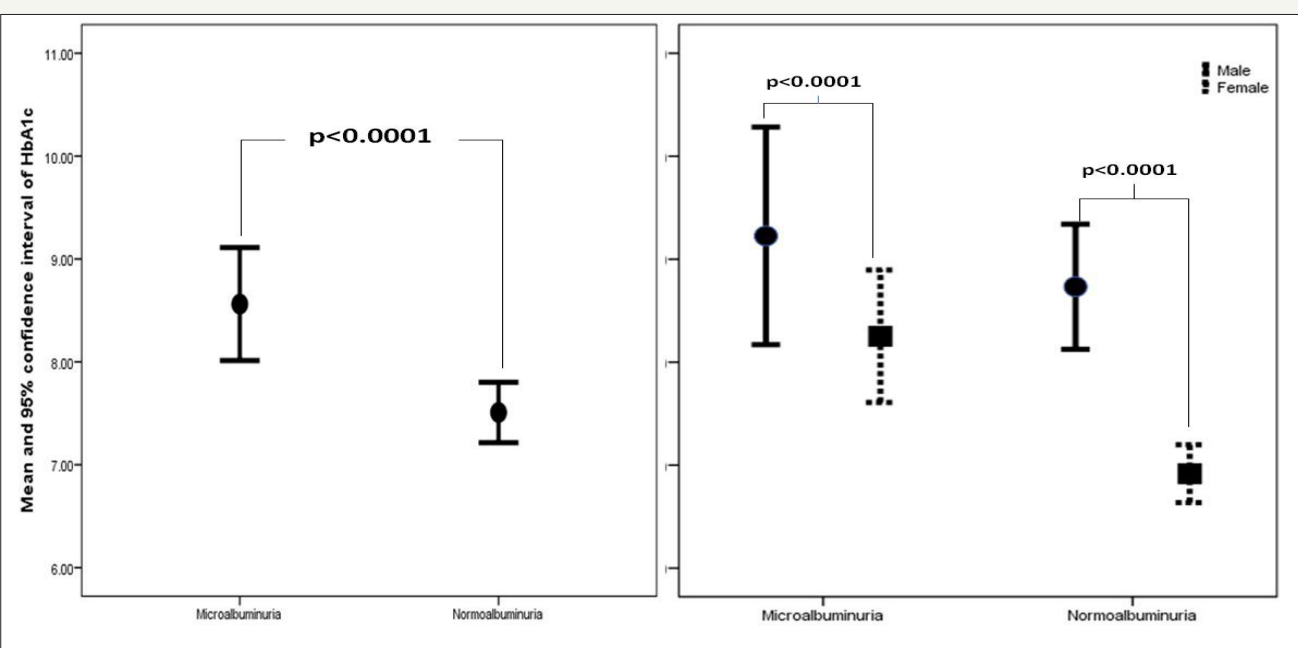

Figures 2: Mean HbA1c of microalbuminuria group and gender.

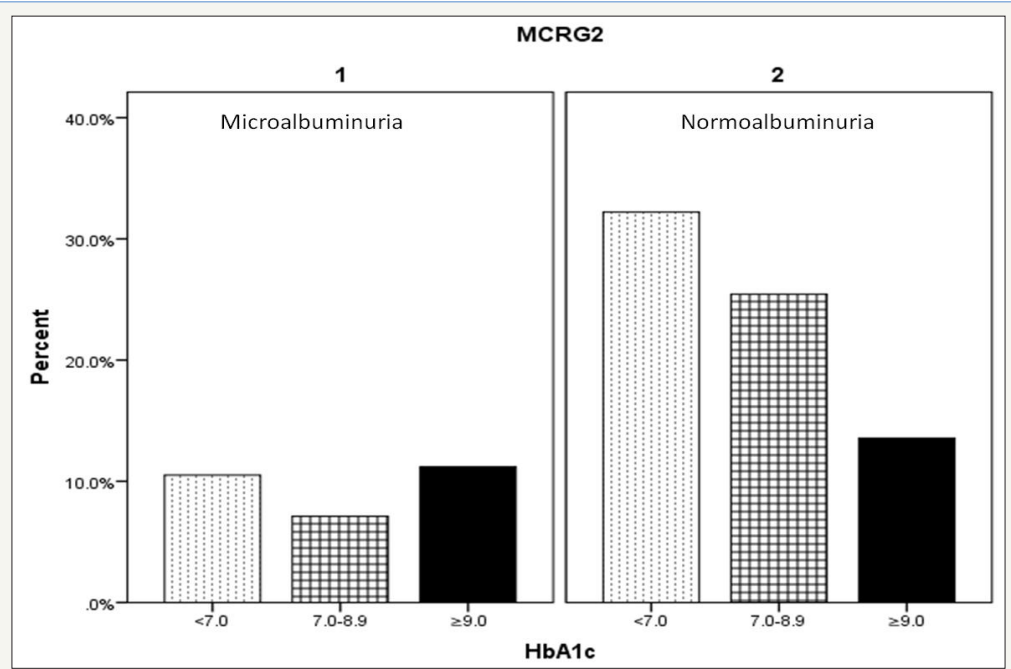

Figures 3: Frequency of Microalbuminuria group according to HbA1c groups. 


\section{Discussion}

Diabetes mellitus is one of the most frequent chronic diseases in adult, the seriousness of which is still often not recognized, although the complications that the condition implies can be very damaging as well as costly and are often brought on by a lack of knowledge about the condition and lack of care [22]. T1DM leads to an increased risk of morbidity and early mortality due to chronic complications affecting both the micro- and macro vasculature. 2 DN is one of the most serious chronic complications of T1DM, affecting approximately $20-30 \%$ of patients and increasing the risk of cardiovascular disease and end-stage renal disease $[3,4]$. DN consists of several stages. Early MA is considered to be one of its most important predictors and is also associated with the development of cardiovascular disease [23,24]. Furthermore, the progressive decline of renal function in patients with T1DM is an early event that occurs in a large proportion of patients with MA [25]. Metabolic and hemodynamic factors contribute to the development of DN, probably by interacting with a genetic susceptibility $[26,27]$.

We have shown high frequency of MA in T1DM to be $29.6 \%$. Various epidemiological and cross-sectional studies have reported marked variation in the prevalence of MA. Compared to international rates, this result was far more than reported in many countries worldwide including 3.3\% in USA in 2015, 5\% in UK and $3.3 \%$ in German diabetic children [17-19]. These were comparable to $13 \%$ reported in west Australian children with T1DM and $13.4 \%$ reported in Indian children $[28,29]$. The need for nationwide and larger scale studies are essential to assess the cost-effectiveness of such early and frequent screening.

Male gender was found to be a risk factor for DN in adult diabetic patients while female gender was a risk factor in adolescent patients with T1DM [29]. Studies on German and Swiss children with T1DM concluded that male gender is a risk factor of DN $[17,30]$. Other studies had concluded that female sex is a risk factor for development of MA [17,31,32]. Our finding was inconsistent with previous studies as MA was found to be nonsigificantly more common in females. Females constitute $69 \%$ of our studied population; therefore, this result can be attributed to gender bias in recruited patient.

The mean age for MA patients was $26.3 \pm 3.0$ and for normoalbuminuric patients was $25.6 \pm 3$.6. This difference in mean age of both groups was not statistically significant. In addition to that, the frequency of MA increases nonsignificantly with increasing age of diabetic patients $(r=0.03, p=0.6)$, this result is in disagreement with other studies in other countries like Italy, Finland, UK and France which had revealed that the age is a risk factor for development of MA and onset of diabetic nephropathy. In a longitudinal study done in UK, it was found that the cumulative probability for developing MA was $40 \%$ after 11 years of age [3336].

The influence of blood pressure on MA in children with T1DM was evaluated and there was no significant difference between microalbuminuric and normoalbuminuric patients in relation to the mean systolic and diastolic blood pressure in disscordance with us. Various studies have revealed conflicting results, some of these studies did not show any significant role of blood pressure on MA, while others have revealed that high blood pressure especially diastolic pressure is one of important predictors of developing MA $[17,33,37]$.

Few studies have investigated the association between MA and body mass index. In our study, there was no significant difference in body mass index between microalbuminuric and normoalbuminuric patients. This results is in agreement with the result of the study done in Denmark while this result was in contrast to studies in Finland, and Sweden, who had demonstrated that patients with MA have a higher BMI than normoalbuminuric patients and controls. Insulin resistance is associated with both central obesity and MA and may play a prominent mediating role [31,37-39].

Glycemic control is one of the important predictors of the development of MA in T1DM and poor glycemic control is a wellknown risk factor of DN. While MA can be substantially delayed by tight glycemic control, achieving the degree of control encouraged by the results of the Diabetes Control and Complications Trial remains impractical for many centers. Additionally, there are claims that there is a glycemic threshold below which the risk of progression to MA remains static, and although not confirmed by other reports. [40-43]. In this study, the mean HbA1C of MA patients is $8.6 \pm 2.5$ which is significantly higher than that of the normalbuminuric patients, $7.5 \pm 2.2(\mathrm{P}<0.0001)$. Although, the study has shown that the frequency of MA increases nonsignificantly with the increase in the level of $\mathrm{HbA1C}(\mathrm{r}=0.1, \mathrm{p}=0.6)$. Other studies also have concluded that $\mathrm{HbA1C}$ is a determinant risk factor for $\mathrm{MA}$, and that poor glycemic control predisposes to MA [17,44-48]. The finding of a higher mean HbA1c in our albuminuric patients which supports the fact that MA is, most likely, due to poor glycemic control. Nevertheless, it is believed that the accelerated early onset DN cannot solely be explained on the basis of poor glycemic control and other factors, such as genetic and environmental, might play a major role in its pathogenesis.

Apart from well-known risk factors such as HbA1c, there were no associations were also observed with fasting lipid parameters. Data from previous cross-sectional studies show that lipids are abnormal in patients with MA and LDL cholesterol are elevated in those at risk of subsequent MA [49,50]. Interestingly, in discordance with other reports, while many of the lipid parameters measured here are negatively correlated, it is striking that only total cholesterol correlates significantly ( $\mathrm{r}=-0.1, \mathrm{p}=0.02)$.

One of the limitations of this study is that it is a clinic based study. This could have introduced some degree of referral bias. However the prevalence of MA is similar to that reported in other studies. MA detection was based on a single urine spot collection with semi quantitative dipstick determinations. The ADA guidelines acknowledge that this technique has acceptable sensitivity and specificity, but recommend that positive tests be reconfirmed with more specific methods and, due to the marked day-to-day variability, that several collections should be done in a 3 to 6 month period before designating a patient as having MA [5]. 
We conclude that the frequency of MA in patients with T1DM in this study is high. It is mandatory to have adequate diagnostic, therapeutic and educational resources in addition to competent physicians who can manage MA in diabetic patients by using a continuing, comprehensive and coordinated approach.

\section{References}

1. (2015) IDF Diabetes Atlas In: $\left(7^{\text {th }}\right.$ edn), International Diabetes Federation.

2. (1991) Diabetes Epidemiology Research International Mortality Study Group: International evaluation of cause-specific mortality and IDDM. Diabetes Care 14(1): 55-60.

3. Tuomilehto J, Borch JK, Molarius A, Fprsén T, Rastenyte D, et al. (1998) Incidence of cardiovascular disease in type 1 (insulin dependent) diabetic subjects with and without diabetic nephropathy in Finland. Diabetologia 41(7): 784-790.

4. American Diabetes Association (2018) Microvascular complications and foot care: standards of medical care in diabetes-2018. Diabetes Care 41(Suppl 1): S105-S118.

5. Bogdanovic' R (2008) Diabetic nephropathy in children and adolescents. Pediatr Nephrol 23(4): 507-525.

6. Hovind P, Tarnow L, Rossing P, Jensen BR, Graae M, etal. (2004) Predictors for the development of microalbuminuria and macroalbuminuria in patients with type 1 diabetes: inception cohort study. BMJ 328(7448): 1105-1109.

7. Vergouwe Y, Soedamah SS, Zgibor J, Chaturvedi N, Forsblom C, et al. (2010) Progression to microalbuminuria in type 1 diabetes: development and validation of a prediction rule. Diabetologia 53(2): 254-262.

8. Chiarelli F, Trotta D, Verrotti A, Mohn A (2002) Treatment of hypertension and microalbuminuria in children and adolescents with type 1 diabetes mellitus. Pediatric Diabetes 3(2): 113-124.

9. Bangstad HJ, Osterby R, Dahl Jorgensen K, Berg KJ, Hartmann A, et al. (1993) Early glomerulopathy is present in young, type 1 (insulindependent) diabetic patients with microalbuminuria. Diabetologia 36(6): 523-529.

10. Viberti GC, Jarrett RJ, Keen H (1982) Microalbuminuria as prediction of nephropathy in diabetics. Lancet 2(8298): 611.

11. Borch Johnsen K, Kreiner S (1987) Proteinuria: value as predictor of cardiovascular mortality in insulin dependent diabetesmellitus 294(6588): 1651-1654.

12. Krolewski AS, Warram JH, Christlieb AR, Busick EJ, Kahn CR (1985) The changing natural history of nephropathy in type 1 diabetes. Am J Med 78(5): 785-794.

13. Perkins BA, Ficociello LH, Silva KH, Finkelstein DM, Warram JH, et al. (2003) Krolewski AS. regression of microalbuminuria in type 1 diabetes. N Engl J Med (23): 2285-2293.

14. Schultz CJ, Konopelska Bahu T, Dalton RN, Carroll TA, Stratton I, et al. (1999) Microalbuminuria prevalence varies with age, sex, and puberty in children with type 1 diabetes followed from diagnosis in a longitudinal study. Oxford regional prospective study group. Diabetes Care 22(3): 495-502

15. Steinke JM, Sinaiko AR, Kramer MS, Suissa S, Chavers BM, et al. (2005) The early natural history of nephropathy in Type 1 Diabetes: IIl. Predictors of 5-year urinary albumin excretion rate patterns in initially normoalbuminuric patients. Diabetes 54(7): 2164-2171.

16. Amin R, Williams RM, Frystyk J, Umpleby M, Matthews D, et al. (2005) Increasing urine albumin excretion is associated with growth hormone hypersecretion and reduced clearance of insulin in adolescents and young adults with type 1 diabetes: the Oxford Regional Prospective Study. ClinEndocrinol (Oxf) 62: 137-144.

17. Li L, Jick S, Breitenstein S (2016) Prevalence of diabetes and diabetic nephropathy in a large U.S. commercially insured pediatric population, 2002-2013. Diabetes Care 39(2): 278-284

18. Holl R, Grabert M, Thon A (1999) Urinary excretion of albumin in adolescents with type 1 diabetes: persistent versus intermittent microalbuminuria and relationship toduration of diabetes, sex and metabolic control. Diabetes Care 22(9): 1555-1560.

19. Raile K, Galler A, Hofer S, Herbst A, Dunstheimer D, et al. (2007) Diabetic nephropathy in 27,805 children, dolescents and adults with Type 1 diabetes: Effect of diabetes duration, A1C, hypertension, dyslipidemia, diabetes onset and sex. Diabetes Care. 30: 2523-2528.

20. Gallego P, Bulsara M, Frazer F, Lafferty AR, Davis EA, et al. (2006) Prevalence and risk factors for microalbuminuria in a population-based sample of children and adolescents with T1DM in Western Australia. Pediatr Diabetes 7(3): 165-172

21. Poovazhagi V, Senguttuvan P, Padmaraj R (2012) Prevalence of microalbuminuria in children with type 1 diabetes mellitus. Ped on call 9: 43 .

22. ISPAD (2000) Consensus and guidelines for the management of type 1 diabetes mellitus in children and adolescents. Medical forum international. Netherlands, p. 1 .

23. Mogensen CE, Keane WF, Bennett PH, Jerums G, Parving HH, et al. (1995) Prevention of diabetic renal disease with special reference to microalbuminuria. Lancet 346 (8982): 1080-1084.

24. Cooper ME (1998) Pathogenesis, prevention, and treatment of diabetic nephropathy. Lancet 352(9123): 213-219.

25. Perkins BA, Ficociello LH, Ostrander BE, Silva KH, Weinberg J, et al. (2007) Microalbuminuria and the risk for early progressive renal function decline in type 1 diabetes. J Am Soc Nephrol 18(4): 1353-1361.

26. Giunti S, Barit D, Cooper ME (2006) Mechanisms of diabetic nephropathy: role of hypertension. Hypertension 48(4): 519-526.

27. Writing team for the Diabetes control and complications trial/ Epidemiology of diabetes interventions and complications research group (2003) Sustained effect of intensive treatment of type 1 diabetes mellitus on development and progression of diabetic nephropathy. JAMA 290(16): 2159-2167.

28. Gallego P, Bulsara M, Frazer F, Lafferty AR, Davis EA, et al. (2006) Prevalence and risk factors for microalbuminuria in a population-based sample of children and adolescents with T1DM in Western Australia. Pediatr Diabetes 7(3): 165-172.

29. Bogdanović R (2008) Diabetic nephropathy in children and adolescents. Pediatr Nephrol 23(4): 507-525.

30. Tebbe U, Bramlage P, Thoenes M, Paar WD, Danchin N, et al. (2009) Prevalence of microalbuminuria and its associated cardiovascular risk: German and Swiss results of the recent global i-search survey. Swiss Med Wkly 139(33-34): 473-480.

31. Riihimaa PH, Knip M, Hirvela TT (2000) Metabolic characteristics and urine albumin-excretion rate in relation to pubertal maturation in type 1 diabetes. Diabetes Metab Res Rev 16 (4): 269-275.

32. Schultz CJ, Konopelska Bahu T (1992) Microabuminuria prevalence varies with age, sex, and puberty in children with type 1 diabetes; follow up from the diagnosis in a longitudinal study. Diabetes Care 22(3): 495502.

33. Moore TH, Shield JP (2000) Prevalence of abnormal urinary albumin excretion in adolescents and children with insulin dependent diabetes mellitus: the MIDAC Study. Arch Dis Child 83(3): 239-243. 
34. Bognetti E, Calori G, Meschi F, Macellaro, Bonfanti, et al. (1997) Prevalence and correlation of early microvascular complications in young type 1 diabetic patients: role of puberty. J Pediatr Endocrinol Metab 10 (6): 587-592.

35. Schuttz CJ, Neil HA, Dalton RN, Dunger (2000) Risk of nephropathy can be detected before the onset of microalbuminuria during the early years after diagnosis of type 1 diabetes. Diabetic Care 23(12): 1811-1815.

36. Amin R, Turner C, van Aken S, Bahu TK, Watts A, et al. (2005) The relationship between microalbuminuria and glomerular filtration rate in young type 1 diabetic subjects: The oxford regional prospective study. Kidney Int 68(4): 1740-1749.

37. Cederholm J, Eliasson B, Nilsson PM, Weiss L, Gudbjörnsdottir S, et al. (2005) Microalbuminuria and risk factors in type 1 and type 2 diabetic patients. Diabetes Res Clin Pract 67(3): 258-266.

38. Mortenson HB (1998) Practical aspects of managing diabetes in adolescents. Acta Pediatr Suppl 425(5): 72-76.

39. De Boer IH, Sibley SD, Kestenbaum B, Sampson JN, Young B, et al. (2007) Central Obesity, Incident Microalbuminuria, and Change in Creatinine Clearance in the Epidemiology ofDiabetes Interventions and Complications Study. J Am Soc Nephrol 18(1): 235-243.

40. (1996) The Diabetes Control and Complications Trial Research Group: The effect of intensive treatment of diabetes on the development and progression of long-term complications in insulin dependent diabetes mellitus. N Engl J Med 329: 977-986.

41. Krolewski AS, Laffel LB, Krolewski M, Maryanne Q James H, et al. (1995) Glycosylated hemoglobin and the risk of microalbuminuria in patients withinsulin-dependent diabetes mellitus. N Engl J Med 332: 1251-1255.

42. (1996) The Diabetes Control and Complications Trial ResearchGroup: The absence of a glycaemic threshold for the developmentof long- termcomplications: The perspective of the diabetes controland complications trial. Diabetes 45(10): 1289-1298.

43. Krolewski A, Laffel L, Krolewski M, Quinn M, Warram JH (1995) Glycosylated haemoglobin and the risk of microalbuminuria in insulin dependent diabetes mellitus. N Engl J Med 332(19): 1251-1255.

44. Schuttz CJ, Neil HA, Dalton RN (2000) Risk of nephropathy can be detected before the onset of microalbuminuria during the early years after diagnosis of type 1 diabetes. Diabetic care 23(12): 1811-1815.

45. Jones CA, Leese GP, Kerr S, Vora JP, Hughes DA, et al. (1998) Development and progression of microalbuminuria in a clinic sample of patients with insulin dependent diabetes mellitus. Arch Dis Child 78(6): 518-523.

46. Gorman D, Schett E, Daneman D (1999) The natural history of microalbuminuria in adolescents with type 1 diabetes. J Pediatr 134(3): 333-337.

47. Svensson M, Eriksson JW, Dahlquist G (2004) Early glycemic control, age at onset, and development of microvascular complications in childhoodonset type 1 diabetes a population-based study in northern Sweden. Diabetes Care 27(4): 955-962.

48. Al Hermi BE, Al Abbasi AM, Rajab MH (2005) Diabetic nephropathy in children with type 1 diabetes mellitus in Bahrain. Saudi Med J 26(2): 294-297.

49. Coonrod BA, Ellis D, Becker DJ, Bunker CH, Kelsey SF, et al. (1993) Predictors of microalbuminuria in individuals with IDDM. Diabetes Care 16(10): 1376-1383

50. Vannini P, Ciavarella A, Flammini M (1998) Lipid abnormalitiesin insulin-dependent diabetic patients with albuminuria. Diabetes Care 7: 151-154.
Creative Commons Attribution 4.0

International License

For possible submissions Click Here

\section{Submit Article}

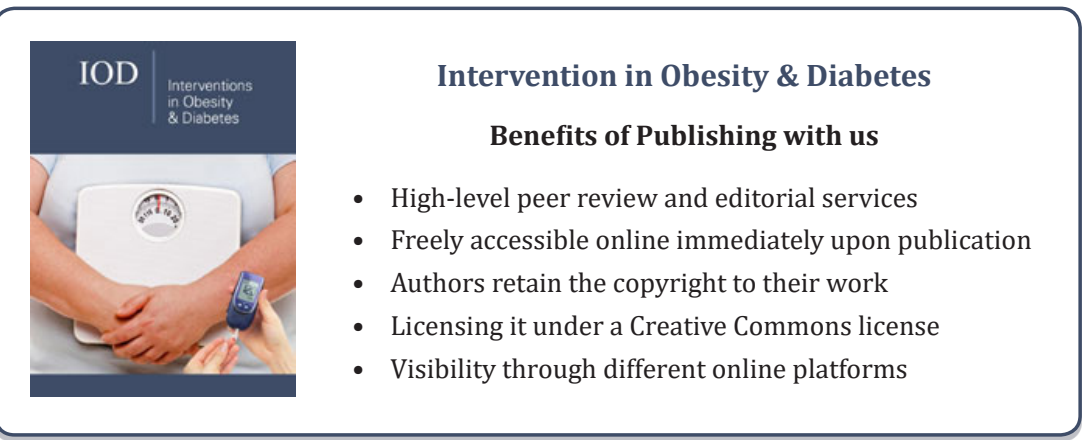

